\title{
ANALISIS TINGKAT KEBISINGAN \\ DI KAWASAN KAMPUS UNIVERSITAS PUTRA INDONESIA (UPI) DI KECAMATAN LUBUK BEGALUNG KOTA PADANG
}

\author{
Fadjar Goembira, Taufiq Ihsan, Muhammad Fahyudi \\ Jurusan Teknik Lingkungan Fakultas Teknik Universitas Andalas \\ Email: fgoembira@ft.unand.ac.id
}

\begin{abstract}
ABSTRAK
Tujuan penelitian adalah menganalisis data pengukuran tingkat kebisingan di kawasan Kampus Universitas Putra Indonesia (UPI). Titik pengukuran eksterior dan interior terdiri atas 12 titik dan 7 titik. Metode pengukuran berdasarkan KepMen LH No. 48 Tahun 1996 tentang Baku Tingkat Kebisingan yaitu metode cara sederhana dengan menggunakan alat Sound Level Meter. Tingkat kebisingan tertinggi eksterior pada saat $L_{1}$ di titik Pintu Gerbang Kampus UPI (1A) sebesar 73,72 $d B(A)$. Tingkat kebisingan pada siang $\left(L_{S}\right)$ antara 69,63-61,60 dB(A), tingkat kebisingan malam $\left(L_{M}\right)$ antara 48,10-38,72 $d B(A)$ dan tingkat kebisingan siang-malam $\left(L_{S M}\right)$ antara 67,91-59,93 $d B(A)$. Tingkat kebisingan interior tertinggi saat aktivitas di Gedung $D(2 B)$ sebesar 69,96 dB(A) sedangkan tingkat kebisingan interior tertinggi saat kosong terjadi di titik Gedung $G(7 B)$ sebesar 69,37 dB(A). Nilai kebisingan eksterior saat waktu $L_{1}-L_{4}$ melebihi Baku Tingkat Kebisingan sedangkan nilai kebisingan interior saat kondisi aktivitas sebagian melebihi Baku Tingkat Kebisingan kecuali Gedung $G(7 B)$ dan nilai kebisingan saat kondisi kosong sebagian melebihi baku tingkat kebisingan kecuali Gedung UPI Sport \& Exhibition Hall (1B), Gedung B (3B) dan Gedung A (4B). Rekomendasi pengendalian eksterior berupa penanaman vegetasi sedangkan pengendalian interior berupa perbaikan konstruksi bangunan.
\end{abstract}

Kata kunci: kebisingan, kampus Universitas Putra Indonesia (UPI), eksterior, interior, rekomendasi alternatif pengendalian

\section{ABSTRACT}

The purpose of this research is to analyze the data measuring the noise level in the campus of the University ofPutra Indonesia (UPI). Measurement point exterior and interior consists of 12 points and 7 points. The measurement method is based on Decree of the Indonesia Minister of Environment No. 48 of 1996 on Baku Noise is a method simple way by using Sound Level Meter. The highest level of exterior noise when $L_{1}$ at the point of the Campus Gate UPI (1A) of $73.72 \mathrm{~dB}$ (A). The noise level in the afternoon $(L S)$ between 69.63 to $61.60 \mathrm{~dB}(\mathrm{~A})$, the noise level night (LM) between 48.10 to 38.72 $d B(A)$ and the day-night noise level (LSM) between 67.91 to $59.93 \mathrm{~dB}(A)$. The highest current interior noise levels of activity in Building $D(2 B)$ of $69.96 \mathrm{~dB}(A)$, while the highest level of interior noise occurs at the point when empty Building $G(7 B)$ of $69.37 d B(A)$. Value exterior noise when the time $L_{1}$ - $L_{4}$ exceeds Raw Noise Level while the value of interior noise when the condition activity partly exceeded Raw Noise except Building $G(7 B)$ and the value of noise when empty condition partly exceeds the noise level except Building UPI Sport \& Exhibition Hall (1B), Building B (3B) and Building $A(4 B)$. Control recommendations exterior form of vegetation while the interior of the control building construction improvements.

Keywords: noise, University of Putra Indonesia (UPI) campus, exterior, interior, control alternative recommendation 


\section{PENDAHULUAN}

Salah satu kawasan yang berpotensi kebisingan adalah kawasan institusi pendidikan yaitu kawasan kampus. Kawasan kampus merupakan suatu kawasan sarana pendidikan mahasiswa, dimana kawasan kampus harus memerlukan kawasan yang tenang dan terhindar dari efek suara yang diakibatkan oleh aktivitas mahasiswa di sekitar area kampus seperti aktivitas transportasi ataupun aktivitas mahasiswa lainnya yang dapat menimbulkan efek suara yang menganggu. Berdasarkan Keputusan Menteri Negara Lingkungan Hidup (KepMenLH) No. 48 Tahun 1996 Tentang Baku Tingkat Kebisingan yaitu tingkat kebisingan yang ditoleransi untuk kawasan Peribadatan dan Institusi Akademik serta sejenisnya yaitu sebesar $55 \mathrm{db}(\mathrm{A})$ dengan penambahan toleransi +3 menjadi $58 \mathrm{db}(\mathrm{A})$.

Kampus Universitas Putra Indonesia (UPI) merupakan suatu universitas swasta yang didirikan di Kawasan Jalan Raya Lubuk Begalung Kota Padang. Kampus UPI terletak pada posisi tepi jalan raya Kota Padang. Kampus UPI memiliki jumlah mahasiswa sekitar 13.022 orang dengan beragam kegiatan yang dilakukan (Universitas Putra Indonesia, 2014).

Jenis aktivitas yang beragam di Kampus UPI meliputi proses pembelajaran mahasiswa, kegiatan di luar kampus (ekstrakurikuler), kegiatan perkantoran, kegiatan pembangunan, kegiatan perdagangan dan kegiatan transportasi. Selain itu, sumber bising yang terdapat di Kampus UPI berasal dari aktivitas transportasi di sekitar area kawasan Kampus UPI. Aktivitas transportasi berasal dari mahasiswa, staff pendidikan, serta warga pendatang yang membawa kendaraan ke lingkungan Kampus UPI. Sumber bising dari aktivitas transportasi berpotensi berpengaruh terhadap kesehatan telinga mahasiswa dan berpengaruh terhadap aktivitas perkuliahan/proses pembelajaran di Kampus UPI. Dari hasil studi pendahuluan tingkat kebisingan eksterior untuk nilai $\mathrm{L}_{\mathrm{S}}$ yang didapatkan pada kawasan Depan Bundaran Kampus UPI berkisar 69,93 $\mathrm{dB}(\mathrm{A})$, Depan Gedung $\mathrm{F}$ kuliah bersama berkisar 69,29 dB(A) dan Depan Gedung Student Center berkisar 69,05 dB(A), sedangkan tingkat kebisingan interior untuk nilai Ls pada gedung $\mathrm{F}$ kuliah bersama didapatkan berkisar 60,26 $\mathrm{dB}(\mathrm{A})$. Dilihat dari hasil pengamatan pada tingkat kebisingan yang didapatkan, baik kebisingan eksterior maupun interior elah melebihi baku tingkat kebisingan.

Dengan adanya potensi sumber bising di kawasan Kampus UPI, maka dilakukannya penelitian terhadap Analisis Tingkat Kebisingan Pada Kawasan Kampus Universitas Putra Indonesia (UPI) Kecamatan Lubuk Begalung Kota Padang. Tujuannya untuk mengidentifikasi sumber bising di kawasan Kampus UPI; mengevaluasi data kebisingan yang didapatkan dengan membandingkan nilai baku tingkat kebisingan untuk daerah kawasan kampus/kawasan pendidikan yang telah ditetapkan oleh KepmenLH No.48 Tahun 1996; serta memberikan rekomendasi pengendalian kebisingan pada kawasan Kampus UPI untuk sumber kebisingan yang tinggi.

\section{METODOLOGI}

Lokasi penelitian dilakukan pada kawasan Kampus UPI di Kecamatan Lubuk Begalung Kota Padang Sumatera Barat. Luas wilayah kawasan Kampus UPI sekitar \pm 15.000 Ha. Kampus UPI memiliki beberapa gedung sebagai fasilitas utama yang beragam sesuai dengan fungsinya masing-masing seperti fasilitas gedung Perkuliahan (A, B, C, D, F, dan G), gedung Perkantoran/Rektorat, gedung Pustaka, gedung Student Center (PKM), gedung Pasca Sarjana, gedung Convention Center, dan gedung Sport \& Exibition Hall. Selain memiliki fasilitas gedung utama, Kampus UPI juga memiliki fasilitas gedung pendukung serta fasilitas lainnya seperti Mushalla, Minimarket, Minicafe, Bank Kampus (Kantor dan ATM) dan Lapangan Basket.

Pengumpulan data dalam penelitian ini meliputi data sekunder dan data primer. Data sekunder berupa peta kawasan Kampus UPI, data jumlah mahasiswa Kampus UPI dan data fasilitas gedung Kampus UPI

Sementara itu, data primer berupa pengukuran tingkat kebisingan di kawasan kampus dan ruang perkuliahan UPI serta jumlah kendaraan. Penentuan titik pengukuran kebisingan berdasarkan area 
yang memiliki potensi besar terjadinya suatu kebisingan. Untuk penentuan titik pengukuran terbagi atas beberapa titik eksterior dan interior.

a. Titik pengukuran bising eksterior

Titik pengukuran bising eksterior terdiri atas 12 titik. Penentuan titik pengukuran eksterior ini berdasarkan pada area yang memiliki potensi bising. Selain itu, teknik pengambilan sampel pada penelitian ini memakai metode simple random sampling atau metode acak. Alasan dalam pemilihan metode ini karena konsep pada metode ini cukup sederhana dan mudah dalam pengerjaannya.

b. Titik pengukuran bising interior

Titik pengukuran bising interior terdiri atas 7 titik. Penentuan titik pengukuran interior berdasarkan pada jumlah gedung dan fasilitas-fasilitas gedung penunjang lainnya di Kampus UPI. Hal ini didasarkan pada titik interior yang berdekatan dengan sumber bising eksterior yaitu aktivitas transportasi. Pada pemilihan titik interior ini dilihat juga pada aktivitas gedung yang dihuni pada saat dilakukannya pengukuran kebisingan interior. Alasannya, pengukuran ini diukur pada saat waktu aktivitas mahasiswa di kampus maupun aktivitas kosong. Lebih lengkap dapat dilihat pada Tabel 1.

Pengukuran tingkat kebisingan eksteriordan interior dilakukan menggunakan alat Sound Level Meter (SLM) memakai bantuan alat penyangga seperti tripod dengan ketinggian 1,2-1,5 m dari permukaan tanah. Tujuannya agar mempermudah surveyor dalam melihat hasil dari output display pada alat SLM. Syarat dalam pengukuran tingkat kebisingan interior, alat diletakkan minimal $1 \mathrm{~m}$ dari dinding dan 1,5 $\mathrm{m}$ dari jendela (Cunnif, 1997). Waktu pengukuran dilakukan mengacu pada KepMenLH No. 48 Tahun 1996 tentang Baku Tingkat Kebisingan.

Analisis dan pembahasan data sebagai berikut:

a. Analisis tingkat kebisingan maksimum dan minimum

Tujuannya untuk mengetahui tinggi atau rendahnya tingkat kebisingan yang terjadi pada kawasan titik pengukuran; b. Evaluasi tingkat kebisingan

Tujuannya untuk mengevaluasi nilai kebisingan yang didapatkan dengan membandingkan pada KepMenLH No. 48 Tahun 1996 tentang Nilai Baku Tingkat Kebisingan. Nilai Baku Tingkat Kebisingan di kawasan kampus yaitu 55 $\mathrm{dB}(\mathrm{A})$ dengan toleransi $+3 \mathrm{~dB}(\mathrm{~A})$ sehingga nilai baku tingkat kebisingan untuk kawasan kampus bernilai 58 $\mathrm{dB}(\mathrm{A})$;

c. Rekomendasi Pengendalian Terhadap Kebisingan

Tujuannya untuk memberikan rekomendasi pengendalian kebisingan jika kawasan tersebut terjadi kebisingan. Pengendalian kebisingan bisa dikendalikan pada sumber bising, media rambatan bising serta penerima bising. Pengendalian ini sangat diperlukan karena efek bising dapat berpengaruh terhadap gangguan pendengaran manusia, psikologis serta konsentrasi belajar.

Tabel 1. Pembagian Titik Pengukuran Kebisingan Eksterior dan Interior Kampus UPI

\begin{tabular}{|c|c|c|}
\hline \multicolumn{3}{|c|}{ No. Titik } \\
\hline \multicolumn{3}{|c|}{ Eksterior } \\
\hline 1. & $1 \mathrm{~A}$ & Pintu Gerbang Kampus UPI \\
\hline 2. & $2 \mathrm{~A}$ & Bagian Selatan Bank Kampus UPI \\
\hline 3. & $3 \mathrm{~A}$ & $\begin{array}{l}\text { Depan Gedung UPI Sport } \\
\text { \&Exibition Hall }\end{array}$ \\
\hline 4. & $4 \mathrm{~A}$ & Depan Convention Center \\
\hline 5. & $5 \mathrm{~A}$ & Depan Gedung Minimarket \\
\hline 6. & $6 \mathrm{~A}$ & Depan Gedung Rektorat UPI \\
\hline 7. & $7 \mathrm{~A}$ & Depan Gedung D \\
\hline 8. & $8 \mathrm{~A}$ & $\begin{array}{l}\text { Depan Gedung } \quad \text { PKM/Student } \\
\text { Center }\end{array}$ \\
\hline 9. & $9 \mathrm{~A}$ & Depan Gedung B \\
\hline 10. & $10 \mathrm{~A}$ & Depan Gedung A \\
\hline 11. & $11 \mathrm{~A}$ & Depan Masjid UPI \\
\hline 12. & $12 \mathrm{~A}$ & Depan Gedung G \\
\hline \multicolumn{3}{|c|}{ Interior } \\
\hline 1. & $1 \mathrm{~B}$ & $\begin{array}{l}\text { Gedung UPI Sport \& Exibition } \\
\text { Center }\end{array}$ \\
\hline 2. & $2 \mathrm{~B}$ & Gedung D \\
\hline 3. & $3 \mathrm{~B}$ & Gedung B \\
\hline 4. & $4 \mathrm{~B}$ & Gedung A \\
\hline 5. & $5 \mathrm{~B}$ & Gedung PKM/Student Center \\
\hline 6. & $6 \mathrm{~B}$ & Masjid UPI \\
\hline 7. & $7 \mathrm{~B}$ & Gedung G \\
\hline
\end{tabular}




\section{HASIL DAN PEMBAHASAN}

Pada Gambar 1 terlihat bahwa beberapa nilai beban kebisingan dari waktu pengukuran $\mathrm{L}_{1^{-}}$ $\mathrm{L}_{7}$ memiliki beban kebisingan dengan nilai fluktuasi yang berbeda. Nilai kebisingan yang tertinggi lebih dominan pada saat waktu pengukuran $\mathrm{L}_{1}-\mathrm{L}_{4}$ sedangkan nilai kebisingan terendah pada saat waktu pengukuran $\mathrm{L}_{5}-\mathrm{L}_{7}$.
Pada saat waktu pengukuran $\mathrm{L}_{1}$, nilai kebisingan tertinggi berasal dari titik Pintu Gerbang Kampus UPI (1A) dan nilai kebisingan terendah berasal dari titik Depan Gedung G (12A). Nilai kebisingan yang didapatkan berkisar antara 73,72-62,02 $\mathrm{dB}(\mathrm{A})$.
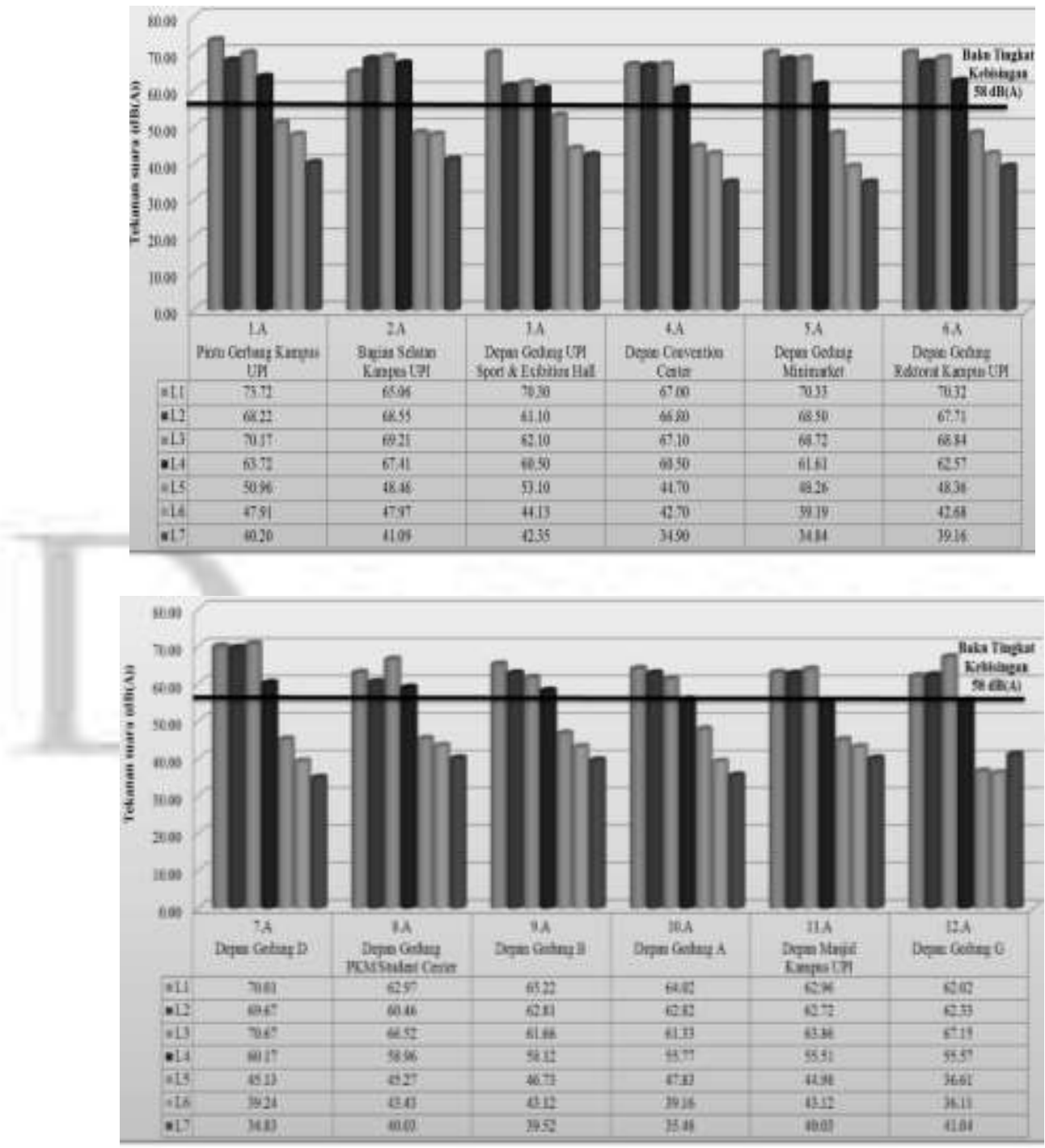

Gambar 1. Tingkat Kebisingan Eksteriordengan Rentang Waktu $\mathrm{L}_{1}-\mathrm{L}_{7}$ di Kawasan Kampus UPI dengan Membandingkan Baku Tingkat Kebisingan sesuai KepMen LH No. 48 Tahun 1996

Untuk nilai kebisingan tertinggi pada saat waktu pengukuran $\mathrm{L}_{2}$ berasal dari Depan Gedung D (7A) sedangkan nilai kebisingan terendah berasal dari titik Depan Gedung PKM/Student Center (8A). Untuk nilai kebisingan yang didapatkan berkisar antara $69,67-60,46 \mathrm{~dB}(\mathrm{~A})$.

Pada saat waktu pengukuran $\mathrm{L}_{3}$ dengan nilai kebisingan tertinggi berasal dari titik Depan
Gedung D (7A) dan nilai kebisingan terendah berasal dari titik Depan Gedung A (10A). Nilai kebisingan yang didapatkan berkisar antara 70,67-61,33 dB(A).

Untuk nilai kebisingan tertinggi pada saat waktu pengukuran $\mathrm{L}_{4}$ berasal dari titik Depan Bagian Selatan Bank Kampus UPI (2A) sedangkan nilai tekanan terendah berasal dari titik Depan Masjid Kampus UPI 
(11A). Untuk nilai kebisingan yang didapatkan berkisar antara 67,41-55,51 $\mathrm{dB}(\mathrm{A})$.

Pada saat waktu pengukuran $\mathrm{L}_{5}$ nilai kebisingan tertinggi berasal dari titik Depan Gedung UPI Sport \&Exhibition Hall (3A) dan nilai kebisingan terendah berasal dari titik Depan Gedung G (12A). Untuk nilai kebisingan yang didapatkan berkisar antara 53,10-36,61 dB(A).

Untuk nilai kebisingan tertinggi pada saat waktu pengukuran $\mathrm{L}_{6}$ berasal dari titik Bagian Selatan Bank Kampus UPI (2A) sedangkan nilai kebisingan terendah berasal dari titik Depan Gedung G (12A). Untuk nilai kebisingan yang didapatkan berkisar antara 47,97-36,11 dB(A).

Pada saat dilakukan pengukuran $\mathrm{L}_{7}$, kebisingan dengan nilai tertinggi berasal dari titik Depan Gedung UPI Sport \&Exhibition Hall (3A) dan nilai kebisingan terendah berasal dari titik Depan Gedung D (7A). untuk nilai kebisingan yang didapatkan berkisar antara 42,40-34,83 dB(A).

Pada siang hari memiliki beban kebisingan yang lebih tinggi dibandingkan beban kebisingan pada kondisi malam hari. Hal ini karena kondisi siang hari, aktivitas kendaraan dan aktivitas lainnya di sekitar kawasan Kampus UPI seperti aktivitas hunian mahasiswa disekitar kawasan Kampus UPI berpengaruh terhadap nilai kebisingan pada siang hari sedangkkan nilai kebisingan pada kondisi malam memiliki beban kebisingan terendah karena pada saat pengukuran di dalam kawasan Kampus UPI tidak terdapat aktivitas mahasswa, dosen pengajar, staff Kampus UPI serta hunian orang lainnya di kawasan Kampus UPI. Selain itu, ada beberapa titik seperti Depan Pintu Gerbang Kampus UPI (1A), Bagian Selatan Bank Kampus UPI (2A) serta Depan Gedung UPI Sport \&Exhibition Hall (3A) terdapat suara aktivitas kendaraan dari luar kawasan Kampus UPI yaitu jalan penghubung Lubuk Begalung-Simpang Haru yang dekat dengan ketiga titik tersebut sehingga berpeluang bertambahnya kebisingan. Hasil dari pengukuran tingkat kebisingan di kawasan Kampus UPI, kondisi pada siang hari dengan jangka waktu pengukuran $\mathrm{L}_{1}-\mathrm{L}_{7}$ memiliki beban kebisingan yang melebihi baku tingkat kebisingan yang telah ditetapkan berdasarkan KepMen LH No. 48 Tahun 1996, sedangkan kondisi malam hari dengan rentang waktu pengukuran $\mathrm{L}_{5}-\mathrm{L}_{7}$ memiliki beban kebisingan yang tidak melebihi baku tingkat kebisingan. Hal ini karena kondisi pada malam hari tidak terdapat aktivitas di dalam kawasan Kampus UPI seperti aktivitas kendaraan, aktivitas mahasiswa lainnya serta aktivitas hunian Kampus UPI sehingga kondisi malam hari tidak terlalu dipermasalahkan. Nilai kebisingan interior tertinggi pada saat waktu $\mathrm{L}_{4}(17.00-22.00)$ dalam kondisi aktivitas yaitu pada titik Gedung PKM/Student Center (5B) dan nilai kebisingan terendah berasal dari titik Gedung B (3B) dengan kebisingan yang dihasilkan berkisar antara 62,69-67,22 $\mathrm{dB}(\mathrm{A})$.

Adapun beberapa gedung kuliah yang tidak dipergunakan pada saat waktu pengukuran $\mathrm{L}_{3}$ (14.00-17.00) yaitu titik Gedung UPI Sport \&Exhibition Hall (1B) dan waktu pengukuran $\mathrm{L}_{4}$ (17.00-22.00) yaitu titik Masjid Kampus UPI (6B), Gedung A (4B) dan Gedung G (7B) karena gedung ini tidak dipakai pada saat waktu pengukuran $\mathrm{L}_{3}$ (14.00-17.00) dan $\mathrm{L}_{4}$ (17.00-22.00) dan tidak ada aktivitas di dalam gedung tersebut serta gedung ini dikunci oleh pihak Kampus UPI untuk kebaikan fasilitas gedung di Kampus UPI.

Hasil grafik pada Gambar 2 dibandingkan terhadap KepMen LH No. 48 Tahun 1996, nilai kebisingan yang dihasilkan beberapa di dalam gedung Kampus UPI memiliki beban suara yang melewati baku tingkat kebisingan. Hal ini karena selain pengaruh suara mahasiswa dan dosen pengajar pada aktivitas akademik di dalam Kampus UPI, adapula pengaruh kebisingan dari aktivitas di luar Kampus UPI yang terdengar sampai ke dalam ruangan. Dilihat dari struktur pintu pada beberapa Gedung di Kampus UPI meliputi Gedung $\mathrm{G}$ dan Gedung $\mathrm{B}$ mengalami sedikit kerusakan yang mengakibatkan beberapa pintu di gedung terdapat lubang. Meskipun beberapa gedung kuliah memakai fasilitas pendingin ruangan (AC), kebisingan dari aktivitas di luar ruangan beberapa gedung dapat terdengar di dalam ruangan akibat pengaruh lubang dari 
kerusakan pintu pada beberapa gedung perkuliahan. Struktur bangunan pada Masjid Kampus UPI memiliki jenis ventilasi/jendela ruangan dalam kondisi terbuka tanpa katup

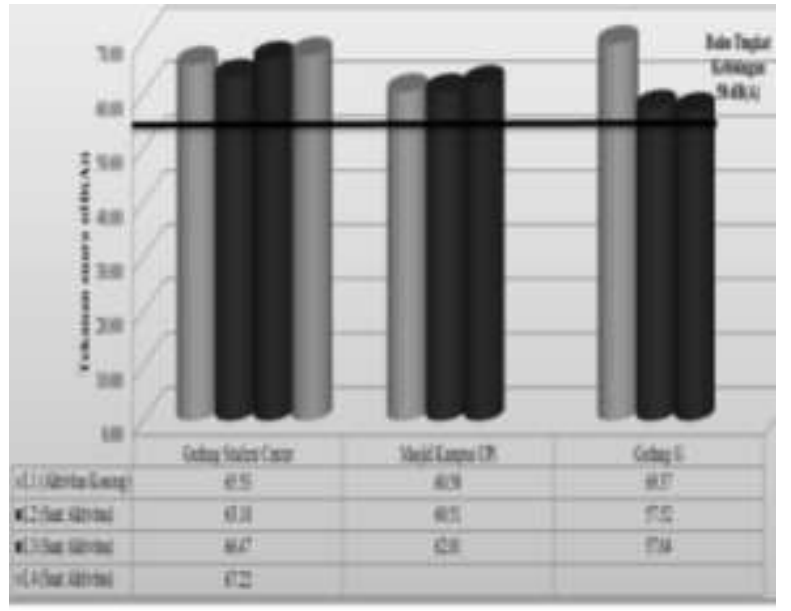

penutup/pembuka jendelanya sehingga kebisingan luar dari aktivitas kendaraan masuk melalui ventilasi yang tidak memakai katup penutup jendelanya.

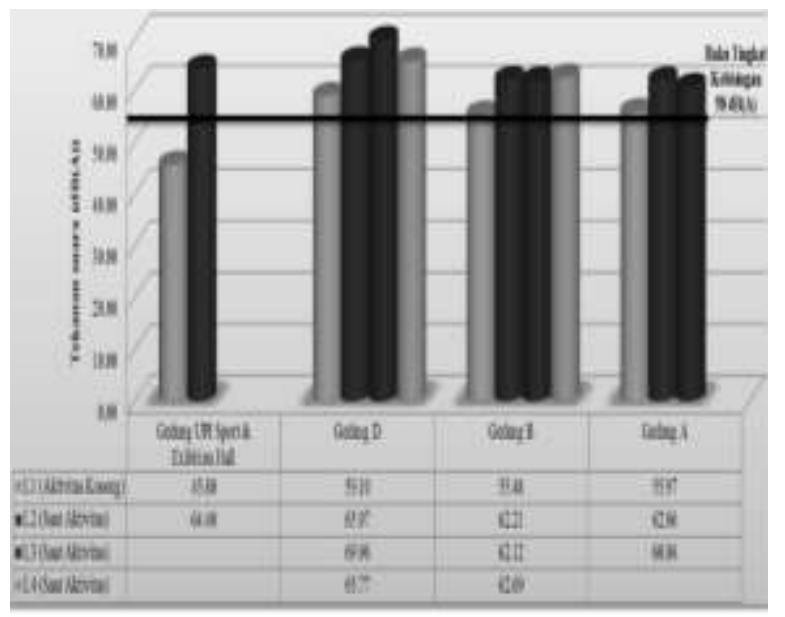

Gambar 2. Perbandingan Tingkat Kebisingan Interior Saat Aktivitas dan Aktivitas Kosong dengan Membandingkan Baku Tingkat Kebisingan Sesuai KepMenLH No. 48 Tahun 1996

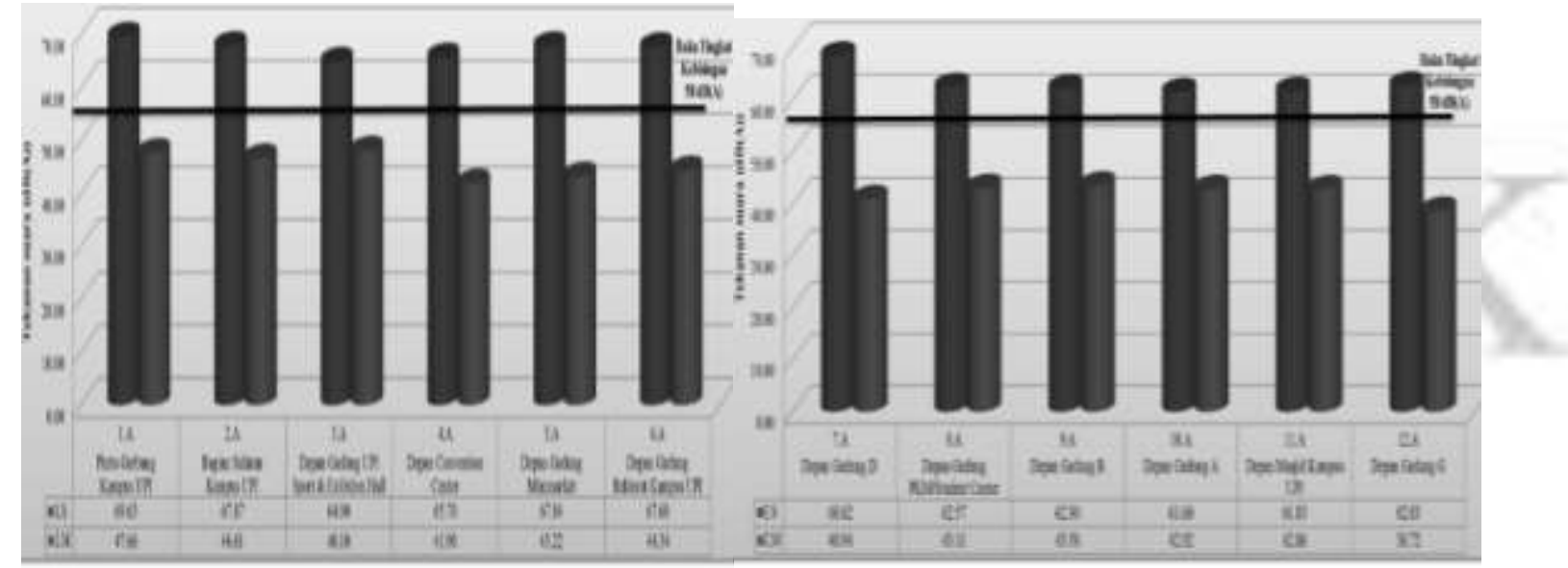

Gambar 3 Tingkat Kebisingan Eksterior pada $\mathbf{L}_{S}, \mathbf{L}_{M}$ dengan Membandingkan Baku Tingkat Kebisingan Sesuai KepMenLH No. 48 Tahun 1996

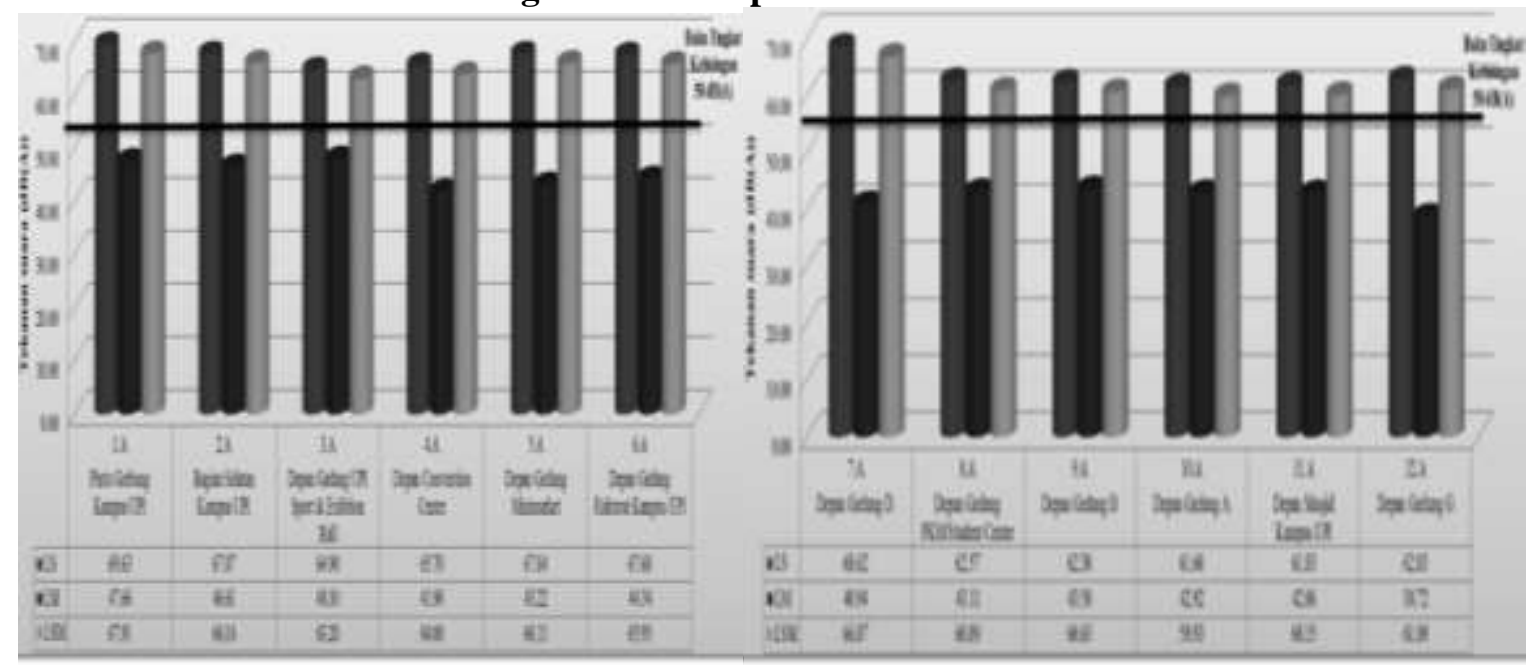

Gambar 4 Kebisingan Sesuai KepMenLH No. 48 Tahun 1996 
Dilihat dari Gambar 3 menunjukkan bahwa nilai pada grafik tingkat kebisingan pada saat $L_{S}$ dan $L_{M}$ pada masing-masing titik pengukuran memiliki fluktuasi tingkat kebisingan yang bervariasi. Tingkat kebisingan yang paling berfluktuasi atau tingkatan selisih $\mathrm{L}_{\mathrm{S}}$ dan $\mathrm{L}_{\mathrm{M}}$ yang tertinggi yaitu pada titik Depan Gedung D (7A) dengan kebisingan sekitar 27,68 $\mathrm{dB}(\mathrm{A})$ sedangkan tingkatan selisih $\mathrm{L}_{\mathrm{S}}$ dan $\mathrm{L}_{\mathrm{M}}$ yang terendah yaitu titik Depan Gedung UPI Sport \&Exibition Hall (3A) dengan kebisingan sekitar 16,80 dB(A). Hal ini disebabkan karena sumber kebisingan yang dihasilkan dari aktivitas kendaraan pada siang hari sangat berpengaruh terhadap grafik fluktuasi $\mathrm{L}_{\mathrm{S}}$, sedangkan pada $\mathrm{L}_{\mathrm{M}}$ tidak ada aktivitas di dalam Kampus UPI sehingga tidak terlalu dipermasalahkan kebisingannya.

Berdasarkan Gambar 4 memperlihatkan pada $\mathrm{L}_{\mathrm{S}}, \mathrm{L}_{\mathrm{M}}$ dan $\mathrm{L}_{\mathrm{SM}}$ untuk kebisingan $\mathrm{L}_{\mathrm{S}}$ bernilai hampir sama dengan kebisingan pada $\mathrm{L}_{\mathrm{SM}}$. Perbandingan nilai $\mathrm{L}_{\mathrm{S}}$ lebih tinggi sedikit dengan nilai $\mathrm{L}_{\mathrm{SM}}$. Sedangkan untuk nilai kebisingan pada $L_{M}$ bernilai jauh lebih rendah dibandingkan dengan grafik $\mathrm{L}_{\mathrm{S}}$ dan $\mathrm{L}_{\mathrm{SM}}$.

Pada pengukuran kebisingan eksterior dan interior dilakukan secara bersamaan dengan rentang waktu yang berbeda. Pengukuran tingkat kebisingan eksterior dilakukan selama 24 jam $\left(\mathrm{L}_{1}-\mathrm{L}_{7}\right)$ sedangkan pengukuran tingkat kebisingan interior dilakukan selama 16 jam $\left(\mathrm{L}_{1}-\mathrm{L}_{4}\right)$ pada saat adanya aktivitas dan aktivitas kosong di kawasan Kampus UPI.

Gambar 5 menunjukan bahwa nilai kebisingan $\left(\mathrm{L}_{\mathrm{eq}}\right)$ pada eksterior lebih tinggi dibandingan pada interior. Dari grafik Gambar 7 ini menunjukan bahwa sebagian titik pengukuran interior memiliki kebisingan tertinggi pada saat aktivitas kosong

Setelah diamati, nilai kebisingan aktivitas kosong ini penyebabnya karena aktivitas mahasiswa di sekitar titik gedung yang diukur. Gedung PKM/Student Center (5B) ini memiliki beberapa ruangan yang dipakai berbagai organisasi mahasiswa UPI. Pada saat dilakukan pengukuran aktivitas kosong, aktivitas mahasiswa diruangan sebelah terdengar sampai ke titik pengukuran sehingga fluktuasi kebisingan pada aktivitas kosong menjadi tinggi sedangkan titik Gedung $\mathrm{G}$ merupakan suatu gedung yang dipakai untuk kegiatan perkuliahan. Pada saat pengukuran aktivitas kosong, aktivitas suara dari luar ruangan di sekitar kooridor dekat ruangan kuliah terdengar dari aktivitas mahasiswa yang menunggu jam kuliah berikutnya.



\section{Analisis Pengaruh Tingkat Kebisingan Terhadap Reseptor}

Setelah observasi lapangan, sumber bising kawasan Kampus UPI yang lebih dominan yaitu aktivitas transportasi dari mahasiswa, dosen pengajar, staff Kampus UPI serta pengunjung Kampus UPI lainnya. Pada saat pengukuran, tingkat kebisingan yang dikategorikan tinggi pada saat aktivitas siang hari $\left(\mathrm{L}_{\mathrm{s}}\right)$ di titik $(1 \mathrm{~A}, 2 \mathrm{~A}, 3 \mathrm{~A}, 4 \mathrm{~A}, 5 \mathrm{~A}, 6 \mathrm{~A}$ 
dan 7A) dengan tingkat kebisingan berkisar antara 61,83-69,63 dB(A). Jika tingkat kebisingan dipaparkan secara kontinu maka akan berpengaruh terhadap psikologis penghuni Kampus UPI baik di luar gedung maupun di dalam gedung dan dilihat pada Tabel 2.3, untuk tingkat kebisingan berkisar 61,83-69,6 dB(A) untuk dampak kebisingan terhadap manusia yaitu peningkatan frekuensi denyut jantung.

Jika tingkat kebisingan pada titik 1A sekitar 69,63 dB(A) dengan dikurangkan pada Baku Tingkat Kebisingan sesuai KepMen LH No. 48 Tahun 1996 yaitu 58 dB(A) didapatkan sekitar 11,63 $\mathrm{dB}(\mathrm{A})$.

Tingkat kebisingan pada kondisi malam hari $\left(\mathrm{L}_{\mathrm{M}}\right)$ untuk kawasan Kampus UPI berkisar antara 38,72-48,10 dB(A). Dapat dilihat dari nilai tingkat kebisingan yang dihasilkan pada malam hari tidak melebihi baku tingkat kebisingan berdasarkan KepMen LH No. 48 Tahun 1996. Selain itu, kondisi malam hari di kawasan Kampus UPI tidak ada terdapat aktivitas kendaraaan maupun aktivitas lainnya.

Rekomendasi alternatif pengendalian tingkat kebisingan eksterior di kawasan Kampus UPI dilakukan beberapa metode yakni pemindahan lahan parkir yang tidak terlalu dekat dengan ruang perkuliahan serta penanaman media penghalang seperti tanaman/vegetasi alami yang dapat berfungsi untuk menambah penghijauan kampus dan mereduksi kebisingan di Kampus UPI dengan mempertimbangkan KepMen PU No. 16 Tahun 2005. Lebih lengkapnya dapat dilihat pada Tabel 1 .

Rekomendasi alternatif pengendalian tingkat kebisingan interior di kawasan Kampus UPI dilakukan dengan perbaikan konstruksi gedung perkuliahan serta penegakan peraturan dilarang ribut pada mahasiswa serta mengurangi suara yang dihasilkan dari aktivitas kendaraan saat memasuki kawasan kampus.

Tabel 1. Rekomendasi Jenis Vegetasi yang Ditanam dan Prediksi Reduksi Kebisingan

\begin{tabular}{llll}
\hline No. & \multicolumn{1}{c}{ Lokasi } & \multicolumn{1}{c}{$\begin{array}{c}\text { Jenis } \\
\text { Vegetasi }\end{array}$} & $\begin{array}{c}\text { Reduksi } \\
\text { Kebisingan }\end{array}$ \\
\hline 1. & Pintu & Tanaman & $67,91 \mathrm{~dB}(\mathrm{~A})$ \\
& Gerbang & Heliconia sp & menjadi \\
& Kampus UPI & dan & 63,71 \\
\hline
\end{tabular}

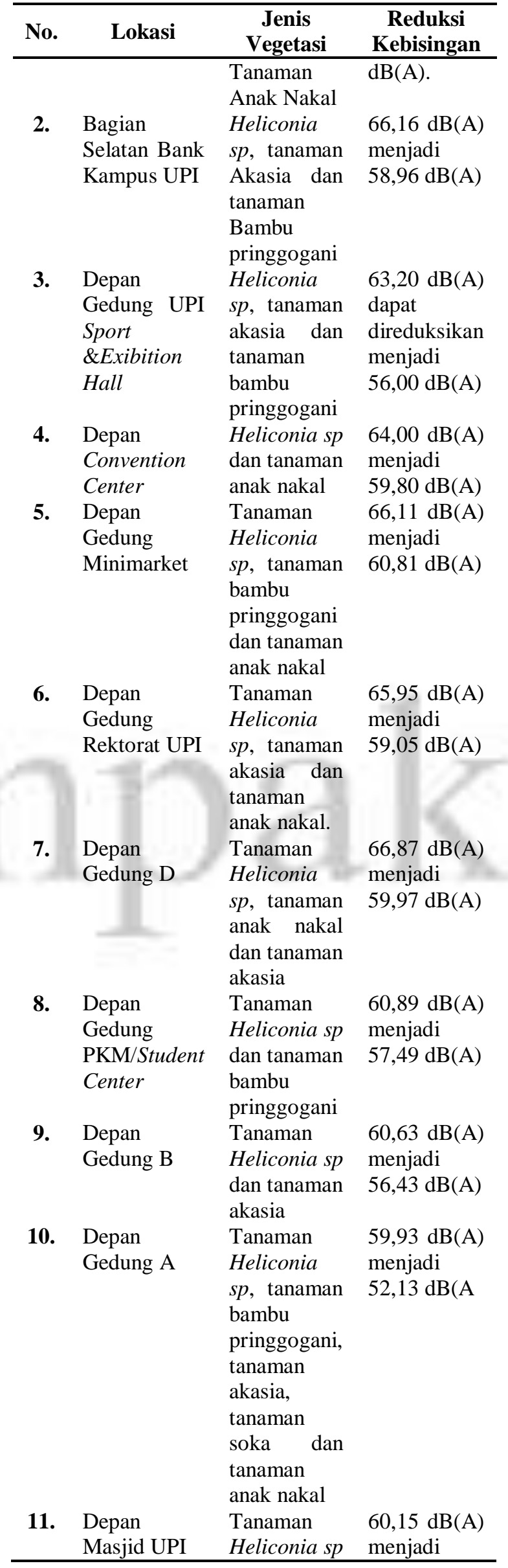




\begin{tabular}{llll}
\hline No. & Lokasi & \multicolumn{1}{c}{$\begin{array}{c}\text { Jenis } \\
\text { Vegetasi }\end{array}$} & $\begin{array}{c}\text { Reduksi } \\
\text { Kebisingan }\end{array}$ \\
\hline & & dan tanaman & $53,95 \mathrm{~dB}(\mathrm{~A})$ \\
12. & Depan nakal & \\
& Gedung G & Tanaman & $61,09 \mathrm{~dB}(\mathrm{~A})$ \\
& Heliconia & menjadi \\
& sp, tanaman & $57,69 \mathrm{~dB}(\mathrm{~A})$ \\
& anak nakal \\
& dan tanaman \\
& bambu \\
& pringgogan \\
\hline
\end{tabular}

\section{SIMPULAN}

Sumber utama kebisingan eksterior yang dihasilkan di kawasan Kampus UPI pada umumnya berasal dari aktivitas kendaraan sedangkan sumber utama kebisingan interior yang dihasilkan di kawasan Kampus UPI pada umumnya berasal dari aktivitas dalam maupun luar ruangan seperti aktivitas komunikasi mahasiswa di area koridoor Gedung kuliah.

Hasil pengukuran tingkat kebisingan didapatkan nilai kebisingan eksterior pada saat kondisi $\mathrm{L}_{1}-\mathrm{L}_{4}$ memiliki beban kebisingan yang melebihi Baku Tingkat Kebisingan KepMen LH No.48 Tahun 1996, sedangkan nilai kebisingan pada saat kondisi pengukuran $\mathrm{L}_{5}-\mathrm{L}_{7}$ memiliki beban kebisingan yang tidak melebihi Baku Tingkat Kebisingan. Sementara itu, nilai kebisingan interior pada saat kondisi aktivitas di dalam ruangan sebagian melebihi Baku Tingkat Kebisingan kecuali pada titik Gedung G (7B) pada saat waktu pengukuran $\mathrm{L}_{2}(09.00-14.00)$ dan $\mathrm{L}_{3}$ (14.0017.00) memiliki nilai kebisingan yang tidak melebihi Baku Tingkat Kebisingan sedangkan perbandingan nilai kebisingan interior saat kondisi kosong sebagian melebihi Baku Tingkat Kebisingan kecuali pada titik Gedung UPI Sport \&Exhibition Hall (1B), Gedung B (3B) dan Gedung A (4B) yang memiliki nilai kebisingan yang tidak melebihi Baku Tingkat Kebisingan.
Rekomendasi alternatif pengendalian tingkat kebisingan eksterior di kawasan Kampus UPI dilakukan beberapa metode yaitu penanaman media penghalang seperti tanaman/vegetasi alami yang dapat berfungsi untuk menambah penghijauan Kampus dan mereduksi kebisingan di Kampus UPI dengan mempertimbangkan KepMen PU No. 16 Tahun 2005 dan mengurangi suara yang dihasilkan dari aktivitas kendaraan saat memasuki kawasan kampus.

\section{DAFTAR PUSTAKA}

Anggraini. 1979. Populasi dan Sampel.

Cunniff. 1977. Environmental Noise Pollution. Jhon Willey and Sons, Canada.

Keputusan Menteri Negara Lingkungan Hidup No. 48 Tahun 1996 Tentang: Baku Tingkat Kebisingan. Jakarta.

Keputusan Menteri Pekerjaan Umum No. 16 Tahun 2005 Tentang Mitigasi Dampak Kebisingan Akibat Lalu Lintas Jalan. 